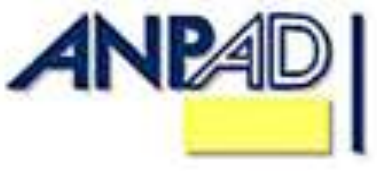

Available online at

http://www.anpad.org.br/bar

BAR, Rio de Janeiro, v. 11, n. 4, art. 1, pp. 364-384, Oct./Dec. 2014

http://dx.doi.org/10.1590/1807-7692bar2014130026

$(\mathrm{cc})$ EY-NG

\title{
Pro-social Motivation beyond Firm Boundaries: The Case of the Genolyptus Network
}

Nicolai Foss

E-mail address: njf.smg@ @bs.dk

Copenhagen Business School SMG Department, Copenhagen Business School, Kilevej 14, DK-2000 Frederiksberg, Denmark.

Rosileia Milagres E-mail address: rosileiam@fdc.org.br

Fundação Dom Cabral - FDC

FDC, Av. Princesa Dianna, 760, Alphaville Lagoa dos Ingleses, 34000-000, Nova Lima, MG, Brazil.

Received 17 September 2013; received in revised form 7 April 2014 (this paper has been with the authors for two revisions); accepted 9 April 2014; published online $1^{\text {st }}$ October 2014. 


\begin{abstract}
An influential body of literature in macro-management research (notably, organization theory and strategic management) associates pro-social motivation solely with firm-like organizations, suggesting that such motivation cannot thrive under more market-like arrangements. We question this argument on theoretical, as well as empirical, grounds. As to the latter, we discuss the specific case of a network of firms in Brazil, the Genolyptus network. We argue that this particular network manifests strong pro-social motivations. This implies that pro-social motivations may thrive beyond corporate boundaries, contradicting the above argument. More constructively, the case of the Genolyptus network points to the importance of intensive communication, rewards that are tied to joint outcomes, knowledge-based authority and consensual decision-making as support arrangements that can build and sustain pro-social motivations in non-firm governance structures.
\end{abstract}

Key words: pro-social motivation; joint production motivation; contractual governance; procedural governance; networks. 


\section{Introduction}

In this paper, we examine the motivational foundations of economic organization, specifically the extent to which the motivations of members differ across governance structures (markets, hybrids, hierarchies; Williamson, 1996). This research question is prompted by a recent influential stream in macro-management theory (in particular, organization theory and strategic management) that casts the main difference between organizations, such as firms, and other kinds of economic organization notably markets - in motivational terms (e.g., Ferraro, Pfeffer, \& Sutton, 2005; Kogut \& Zander, 1996). The basic argument is that motivations differ in kind across different governance structures. Thus, the argument is different from the well-known organizational economics argument that organizations, such as firms, and markets differ in terms of the strength or intensity of their incentives (e.g., Williamson, 1996). Specifically, the argument is that firms can build pro-social motivation among employees, and that non-firm economic organizations (i.e., markets and hybrid) cannot. In fact, the latter may be destructive of such motivation. Pro-social motivation is generally understood to be the motivation to engage in behaviors that benefit others, such as helping, sharing, and donating. The motivation to engage in such behaviors ranges all the way from pure altruism over to more reciprocal motivations to selfinterest (Fehr \& Fischbacher, 2002).

The literature on pro-social motivation spans several research streams in social psychology (e.g., Grant \& Dutton, 2012), behavioral economics (Fehr \& Fischbacher, 2002; Isaac, Mathieu, \& Zajac, 1991), and moral philosophy (e.g., Sandel, 2013). In management research, pro-social motivation is invoked in parts of organizational behavior literature (e.g., LePine, Erez, \& Johnson, 2002), in writings on corporate social responsibility (e.g., Servaes \& Tamayo, 2013), and in organizational theory. In the context of organizational theory, Osterloh and Frey (2000) argue that firms can govern transactions, particularly those relating to the sharing and building of valuable knowledge, in subtle ways that are compromised by the high-powered incentives of the marketplace but make use of the specific pro-social motivation of firms. Lindenberg and Foss (2011) proffer the notion of joint production motivation as a specific kind of pro-motivation that can be called forth by firms. They uniquely associate this kind of motivation with firm-like organizations.

Even within transaction cost economics, Williamson (1996) suggests that a particular feature of firms is their access to low-powered incentives, which facilitates certain types of transactions. Several other contributions, many published in top management research journals, echo or express similar ideas in various ways (e.g., Adler, 2001; Ferraro et al., 2005; Foss \& Lindenberg, 2012; Ghoshal, 2005; Ghoshal \& Moran, 1996; Hodgson, 1998; Kogut \& Zander, 1992, 1996; Nahapiet \& Ghoshal, 1998; Spender, 1996). Further argument asserts that the ability of firms to cultivate pro-social motivation underlie organizational advantage (Nahapiet \& Ghoshal, 1998); that is, firm-like organizations can carry out activities that other kinds of economic organizations are incapable of carrying out (at the same level). Chief among these advantages is knowledge sharing (Osterloh \& Frey, 2000) and knowledge integration (Kogut \& Zander, 1992). In fact, many of the above contributions belong to what is often called the knowledge-based view of the firm (e.g., Spender, 1996). The clear implication of these contributions is that markets and other non-firm governance structures should be used sparingly for the organization of knowledge processes such as innovation, knowledge sharing, knowledge integration, and so on (Kogut \& Zander, 1992).

In this study, we question these ideas, in particular the tight linking of pro-social motivation and governance structure. Specifically, based on 42 semi-structured interviews, we study a single illustrative case, namely the case of a Brazilian inter-firm network, called the Genolyptus Network, that was dedicated to joint innovative projects and partly orchestrated by public organizations. Building on this case, and on theoretical arguments, we suggest that strong pro-social motivation can in fact thrive within non-firm economic organizations, notably in networks. Evolutionary anthropology suggests that humans have been hardwired by evolution to mobilize a specific motivation for cooperating in team-like settings, characterized by a high degree of interdependence and the need for ongoing mutual adjustments. 
However, while many productive activities that take place in firms do indeed have these characteristics, so do many productive activities that cut across firm boundaries, such as supplier relations and network relations between cooperating firms. It may be that what looks like pro-social motivation in such relations (and perhaps even within firms) is in fact entirely selfish in motivation, albeit checked by reputation effects, hostages, and so on ( $c f$. Klein \& Leffler, 1981). Yet, we argue that our case speaks against such an interpretation, and instead in favor of the idea that pro-social motivations can thrive beyond firm boundaries. This requires that individuals who engage in non-firm economic organizations be capable of building support structures that can preserve pro-social motivations. Our case suggests that this is in fact possible, and we discuss the nature of such structures in general.

In sum, we contribute to the recent discussion in macro-management theory about the nature of organizations in general and firms in particular, a discussion that has strongly influenced management research fields such as organization, strategic management and international business theory. We specifically argue that pro-social motivations not only exist, but also thrive outside of the boundaries of the firm, for example, in firm networks, and as such are not unique to firms. In fact, the mechanisms that support pro-social motivations in firms - namely, intensive communication, rewards that are tied to joint outcomes, knowledge-based authority, and consensual decision-making — are also the mechanisms that support pro-social motivations in non-firm governance structures. Given this, we propose a research program dedicated to examining the relative advantages of firms and non-firm economic organizations fostering pro-social motivation and the mechanisms these different governance structures deploy to foster such motivation.

\section{Theoretical Background: Pro-Social Motivation, Organizations, and the Knowledge- Based View}

\section{Pro-social motivation: meaning}

Many streams in management research highlight the pro-social motivation that may thrive in firms. Work on the knowledge-based view of the firm in strategic management, organization theory and other macro-management research fields stress that efficient knowledge production, integration, sharing and so on require high levels of pro-social motivation, that is, the motivation to engage in behaviors that benefit others, such as helping, sharing, and donating. Standard examples of pro-social behavior include donating blood, whistle-blowing, giving money to charities, and general helpful behavior. Such behaviors fundamentally matter to the smooth working of organizations. Helpful employees are an obvious resource that make processes run smoothly because helping others aids in reducing bottlenecks, solving problems and evening out workflows. In the context of knowledge creation, sharing and integration, these knowledge-related activities are inherently hard to measure and incentivize, and thrive best with weak incentives and less-controlling environments (e.g., Osterloh \& Frey, 2000). Research has found that pro-social behaviors stimulate sales performance (Podsakoff \& MacKenzie, 1994), operating efficiency (Walz \& Niehoff, 2000), product quality (Podsakoff, Ahearne, \& MacKenzie, 1997), as well as coordination, innovation, organizational development, and cohesion (see Organ, Podsakoff, \& MacKenzie, 2006).

An additional argument asserts that firms are better capable of building support structures for such motivation and that markets are destructive of it (e.g., Adler, 2001; Ferraro et al., 2005; Foss \& Lindenberg, 2012; Ghoshal, 2005; Ghoshal \& Moran, 1996; Hodgson, 1998; Kogut \& Zander, 1992, 1996; Nahapiet \& Ghoshal, 1998; Spender, 1996). The underlying argument is that firms can decouple efforts and rewards in a way that markets cannot, better build shared knowledge across multiple interacting individuals, and cultivate a sense of shared purpose. Such features strongly support knowledge creation, sharing and integration.

Pro-social motivation is also influential in micro-management research. For example, influential research on organizational citizenship (Deckop, Mangel, \& Cirka, 1999; LePine et al., 2002; Podsakoff 
\& MacKenzie, 1997) points to other-oriented motivation (e.g., helping, sportsmanship, civil virtue). Work on identities in relations (Brewer \& Gardner, 1996; Brickson, 2005, 2007) emphasizes that mutual concern for the interest and outcomes of significant others may be quite salient to employees. In the field of organizational or collective identification (Brewer \& Gardner, 1996; Haslam, Powell, \& Turner, 2000) research emphasizes employees' membership in a collective category, and indicate that belonging to such categories imply that they adopt similar motivations. Some research explicitly link collective goals to the motivation of organizational members. Shamir $(1990,1991)$ coined the notion of collectivistic work motivation, recognizing that organizational members can be motivated in terms of what is beneficial to the organization (or a sub-group within the organization). Literature on teams (e.g., Kozlowski \& Ilgen, 2006; Mathieu, Maynard, Rapp, \& Gilson, 2008) also addresses the special motivation that may be attached to teamwork (i.e., the team spirit phenomenon). Various written works beyond management research also address pro-social motivation, notably social psychology (e.g., Grant \& Dutton, 2012), behavioral economics (Fehr \& Fischbacher, 2002; Isaac et al., 1991), and moral philosophy (e.g., Sandel, 2013).

\section{Pro-social motivation as a distinguishing characteristic of firm organizations}

In spite of considerable attention to pro-social motivation, some key issues have not been sufficiently investigated, and because of this, assumptions that have not been sufficiently examined dominate some key literatures in management research that make use of the pro-social motivation construct, notably the streams of research in organization theory and strategic management theory that cluster around the knowledge-based view of the firm.

An important question concerns the institutional locus of pro-social motivation, specifically whether such motivation can exist beyond the boundaries of organizations. A number of contributions to the theory of the firm in management research, in particular the knowledge-based view, address this issue (e.g., Adler, 2001; Ferraro et al., 2005; Foss \& Lindenberg, 2011, 2012; Ghoshal, 2005; Ghoshal \& Moran, 1996; Hodgson, 1998; Kogut \& Zander, 1992, 1996; Nahapiet \& Ghoshal, 1998; Osterloh \& Frey, 2000; Spender, 1996).

The argument that pro-social motivation is uniquely associated with firms takes several forms. Closest to traditional organizational economics (e.g., Williamson, 1996), Osterloh and Frey (2000) argue that many vital activities, particularly those involving pro-social behaviors (knowledge sharing, helping behaviors) in firms are characterized by a very high measurement in costs. As a result it is very difficult (costly) to define clear measures and measure input and output performance against such data. In fact, attempts to encourage pro-social behaviors in this way may backfire, as explicit performance control can crowd out pro-social and intrinsic motivations, thus reducing the supply of pro-social behaviors (as well as behaviors that thrive on intrinsic motivation, such as creativity and learning). Therefore, firms should cultivate pro-social motivations and refrain from using high-powered performance incentives, particularly when pro-social and/or creative behaviors are involved.

A related argument is that "shared purpose transforms the institutional context in which relations are embedded and, thereby, influences the behaviours and preferences of actors" (Ghoshal \& Moran, 1996, p. 33). Such shared purpose leverages the "human ability to take initiative, to cooperate, and to learn; it also may rely on exploiting the organization's internalized purpose and diversity to enhance both learning and its use in creating innovations and purposive adaptation" (Ghoshal \& Moran, 1996, p. 42). Shared purpose has thus direct motivational connotations; indeed, the shared part directly speaks to pro-social motivations ( $c f$. also Shamir, 1990, 1991). A further argument states that firms

provide the normative territory to which members identify. This identification has two implications. First, it defines the conventions and rules by which individuals coordinate their behaviour and decision making ... Second, identification sets out the process by which learning is developed socially through the formation of values and convergent expectations (Kogut \& Zander, 1996, p. 506). 
These specific virtues of firms are explicitly contrasted with the market. To Ghoshal and Moran (1996), introducing high-powered incentives reminiscent of market organization means implicitly treating employees as potential opportunists, which may set in motion destructive processes of a selffulfilling prophecy (see also Ferraro et al., 2005; Ghoshal, 2005). To Hodgson (1998) and Adler (2001) such incentives destroy internal trusting relationships. To Nahapiet and Ghoshal (1998) and Kogut and Zander (1996), bringing market-like mechanisms into the firm is destructive of the sense of shared purpose and the attendant pro-social motivations. Kogut and Zander (1996, p. 511) summarize this in the following manner:

In the market model, communication consists of the coding and decoding of information, coordination proceeds through transactions governed by prices, and learning is the revelation of cooperative or dishonest reputations. In the view of a firm as embodying social knowledge, coordination is achieved through convergent expectations, communication is characterized by discourse based on rich codes and classifications, and learning is situated.

Ultimately, these organizational advantages are possible because firms can cultivate pro-social motivations, and markets cannot.

\section{The micro-foundations of the argument}

The micro-foundations of the above argument that only firms can build pro-social motivations are seldom spelled out in great detail (in fact, to some extent, we have provided interpretations of what the authors cited above may mean). However, we suggest that the relevant micro-foundations are roughly the following. Firms have a fundamentally team-like dimension (Foss \& Lindenberg, 2012); thus, they are characterized by strong interdependencies in inputs, and by inputs that are difficult to measure ( $c f$. Alchian \& Demsetz, 1972; Osterloh \& Frey, 2000). Moreover, they rely on ongoing mutual adaptation. Such adaptation is supported by shared values and beliefs and pro-social motivations (Nahapiet \& Ghoshal, 1998).

These pro-social motivations provide the basis for pro-social behaviors, that is, actions that are intended to help or benefit the individual, the group, or organization toward which they are directed, are discretionary, and therefore, not recognized by formal evaluation systems (Osterloh \& Frey, 2000). As such, pro-social behaviors are essential to the smooth and intelligent adaptation of firms to changing contingencies. They cannot be called forth by extrinsic motivators, such as promotion, direct orders, or performance-contingent monetary rewards (Brief \& Motowidlo, 1986; Penner, Dovidion, Piliavin, \& Schroeder, 2005; Weinstein \& Ryan, 2010). Trying to deploy extrinsic motivators to stimulate pro-social behaviors may, in fact, be counter-productive, because such motivators risk crowding out pro-social motivations and their resulting behaviors. And yet, pro-social behaviors may be very important to the effective functioning of the organization (Osterloh \& Frey, 2000), as demonstrated by such examples of typical pro-social behaviors like helping colleagues, showing loyalty to the organization, sharing knowledge, exercising civic virtue, and actively engaging in self-development.

In sum, a number of streams in management research make the case that firms can mobilize particular pro-social motivations. Many scholars make the additional, and stronger, case that only firms can mobilize these motivations, and some make the even stronger claim that firms are institutions that are specialized in calling forth these motivations (e.g., Hodgson, 1998; Kogut \& Zander, 1996). However, a number of things are left unclear in these analyses, notably what the antecedents of prosocial motivations are and whether firms are the only governance structures or institutions that can play the role of support structures sustaining pro-social motivations. In this sense, the micro-foundations of the argument that governance structures and pro-social motivations are connected in a systematic way are incomplete. To add to those micro-foundations, we need to be more specific about pro-social motivation and its background. 


\section{Pro-social motivations: goal framing and supporting structures}

From the point of basic economics, pro-social motivation represents a puzzle. It may not be associated with reciprocity and self-interest. Moreover, economics holds that there is a propensity to shirk duty in cooperative ventures, whether concerning teams (Alchian \& Demsetz, 1972) or the supply of public goods. Firms clearly have team-features and many firm-specific assets are like public goods in the sense that they everyone in the firm benefits from them and this does not diminish their supply. Firm-specific capabilities, brands, reputations and so on, are examples. Reviewing the evidence on experimental game-theoretic studies of cooperation (in terms of public good provision), Ledyard (1995, p. 172) concluded that "it is possible to provide an environment in which almost all of the subjects contribute toward the group interest.... Why ... this all works remains a mystery". Apparently, situations exist that somehow prime individuals to adopt group goals and let their behaviors be influenced by such goals. The contributions that we have surveyed, above all, essentially argue that only firms can accomplish this priming.

Based on arguments from evolutionary anthropology, experimental economics and cognitive sociology, Lindenberg and Foss (2011) provide a distinct perspective on such priming. They argue that humans are equipped with capacity for recognizing a situation as one of, what they call, joint production (i.e., team production) and to trigger the special motivational and cognitive faculties to participate in joint production ( $c f$. Sebanz, Bekkering, \& Knoblich, 2006; see also Foss \& Lindenberg, 2012). These authors argue that management of these pro-social motivations - what they call joint production motivation - is primarily a matter of the management of cognitions. They build this argument from goal-framing theory, which applies the insight from (social) cognition research that mental constructs have to be activated in order to affect behavior, and that goals are particularly important mental constructs in which cognitions and motivations are intertwined (e.g., Förster, Liberman, \& Higgins, 2005; Kruglanski \& Köpetz, 2009; Lindenberg, 2008).

Goals govern what individuals attend to (Posner \& Petersen, 1990); what concepts and what kinds of knowledge are being activated; what alternatives we consider; what information we are primarily sensitive to; what we expect others to do, and how we process information (Förster et al., 2005; Gollwitzer \& Bargh, 1996; Kruglanski \& Köpetz, 2009). These processes have a direct influence on motivation, because with one goal being focal, that means that other goals are pushed into the background (Shah, Friedman, \& Kruglanski, 2002), and because goals are associated with different sets of preferences and criteria for evaluating courses of action vis-à-vis meeting goals. Lindenberg and Foss (2011) argue that there is one overarching goal which is connected to a pro-social, supra-individual orientation. They call this the normative goal. It concerns what is appropriate behavior in the context of furthering a collective entity, whether a group, organization, or nation (Moorman \& Blakely, 1995; Van Knippenberg, 2000).The criteria for goal fulfillment are linked to the realization of joint goals and to meeting joint appropriateness standards. When the normative goal is focal, the two competing individual-interest goals are pushed into the cognitive background, which suspends opportunism.

Lindenberg and Foss (2011) discuss a number of management and organizational practices that can initiate and maintain joint production motivation. The first group deals with the preconditions for activating a normative goal frame that is conducive to joint production motivation - namely, the fact that members of an organization perceive their interdependence in terms of joint production (through team and task structure). They include linking task and team structures in a transparent manner to common goals. The second group deals with direct supports for the normative goal frame and mainly encompass cognitive/symbolic management. The third group includes the more indirect supports for the normative goal frame through calibrating reward structures, so that they are explicitly geared towards joint goals. 


\section{Pro-social motivation beyond firms?}

As noted, many influential management scholars argue that pro-social motivations in the context of productive activities are the exclusive province of firms. To provide an anchor for the discussion and examine the reach of this argument, consider the notions of joint production and the attendant joint production motivation (a kind of pro-social motivation triggered by joint production situations) coined by Lindenberg and Foss (2011). Joint production refers to any productive activity that involves heterogeneous but complementary resources and a high degree of task interdependence. Their conception implies that human beings are especially equipped with coordinated cognitive and motivational faculties that are geared to participating in joint production. Individuals who engage in joint production perceive the environment differently than they do in independent action.

Specifically, as Lindenberg and Foss (2011) explain, individuals engaged in joint production recognize a joint endeavor and see themselves as part of this endeavor, each with his or her own roles and responsibilities, involving a sharing of cognitions about the relevant tasks, interdependencies, timing, and possible obstacles in smoothing coordination in terms of joint goals. They are able to mutually anticipate goal-related actions from others and to cognitively coordinate temporal and special aspects of cooperation (Higgins \& Pittman, 2008; Sebanz et al., 2006). They exert intelligent and adaptive efforts - that is, they engage in problem-solving and helping efforts that result in productivity gains and innovativeness. They are willing to supply inducement and assistance to others to make them do their bit (Tomasello, Carpenter, Call, Behne, \& Moll, 2005), and to sanction them if they do not (Ostrom, Walker, \& Gardner, 1992). In ambiguous situations, group members will search for ways to serve the group goal(s), rather than waiting to be instructed (De Dreu, Nijstad, \& Knippenberg, 2008; Wrzesniewski \& Dutton, 2001), and they are heedful of their and others' contribution to collective goals (Weick \& Roberts, 1993).

It is not immediately obvious why joint production can't take place outside firm boundaries, nor why the required joint production motivation cannot thrive in, for example, a network of firms. Indeed, as Frey, Luethi and Osterloh (2011) show, community enterprises, such as open-source software production and Wikipedia, are not firms; yet, they are built, at least to some extent, on pro-social motivations (more ego-centric motivations may be relevant to the extent that, e.g., contributing to the community enterprise furthers one's career). It may be countered that the crucial difference between open-source networks and firms is that, as to the latter, there is a fixed membership, whereas to the former, members self-select themselves in and out. This means that for open-source networks, problems of overstretching team size does not occur. Moreover, community enterprises often function exactly because productive activities are highly modular, as in markets. In contrast, firms may arise when productive activities require close coordination, often involving co-specialization and asset specificity problems (Williamson, 1996). However, the point here is that, perhaps strongly, pro-social motivation is possible in the context of non-firm commercial transactions. In order to understand whether joint production and the motivation for it (and, more broadly, pro-social motivations) may thrive beyond the boundaries of the firm, and what this requires, we discuss a specific fixed-membership network.

\section{Pro-Social Motivation in a Network: The Genolyptus Case}

\section{Method: data and analysis}

We adopt a small (one-N) research design in our examination of pro-social motivation in a network. Such designs are sometimes seen as slightly suspect, because of external validity problems deriving from sample bias (King, Keohane, \& Verba, 1994). However, our basic purpose is to document the existence of strong pro-social motivations in the context of joint production in a non-firm setting. Moreover, as Dyer and Wilkins (1991, p. 617) explain, if executed well, case studies can be "extremely powerful" when "authors have described general phenomenon so well that others have little difficulty 
seeing the same phenomenon in their own experience and research". In other words, good case descriptions may succeed in identifying generative mechanisms other researchers can recognize in the cases they investigate (Hedström, 2005). To do this, however, it is usually necessary to "provide a rich description of the social scene, to describe the context in which events occur, and to reveal ... the deep structure of social behavior" (Dyer \& Wilkins, 1991, p. 615).

Accordingly, we report on the findings from a longitudinal field study conducted between 2004 and 2008. The field study relied on participation of network representatives. In all, 42 semi-structured interviews were conducted (Appendix), with a total of 65 hours of transcriptions. In addition to this, a significant part of the collective memory of the network, as represented by more than 3,200 e-mails exchanged between the members, and all the official documentation produced were analysed. Documents and information produced during the interviews were analyzed using the software $\mathrm{N}$ Vivo, which helped us organize the data. The techniques used were content analysis (Krippendorff, 2004) and the constant comparative method (Strauss \& Corbin, 1990). Establishing the categories of analysis was the result of a joint effort between the researchers involved. Specifically, one researcher proposed the categories of analysis and these categories were refined through further discussions and an ongoing dialogue with the case material.

All these techniques enhanced our interpretation and allowed generating categories that integrate the theoretical framework and explain the observed phenomenon (Langley, 1999). Based on these techniques, we developed a data structure which consisted of three groups, namely, data on the (a) contractual, (b) procedural governance and (c) industry contexts. These groups were then subdivided, part of them pre-selected according to the theoretical background and the other part from an inductive process. The latter introduced the theme of joint production motivation. Thus, documents and interviews conducted in the first and second phase greatly contributed to understanding team design, the goals pursued, and the tasks performed in the network. For example, in the second phase, an important point stressed in the interview with the Genolyptus' coordinator was the interdependences within and across the individuals involved in different network projects. From the interviews performed during the third phase, documents about the context in which the Genolyptus was placed and e-mails, we collected evidence concerning symbolic management, reward structures, and authority design in the network. In sum, these techniques enhanced our interpretation and allowed the production of categories that integrated the theoretical framework and helped to explain the phenomena observed in the Genolyptus network.

The empirical research effort was carried out in three stages. In the first stage, nine interviews were conducted and the objective was to obtain a generic understanding of how the network was structured, the activities of its members and their objectives. The interviews lasted between 45 and 140 minutes and were recorded and transcribed. Following the comparative method, over time the scripts of the interviews were adjusted (Strauss \& Corbin, 1990). This helped refining the analysis and adding categories to our theoretical perspective. In the second stage, access was granted to the complete set of documents that were produced during the history of the network (i.e., all emails, reports, minutes of meetings, evaluations, contracts and their annexes). Then, new interviews with the coordinator were conducted to confirm initial understanding and drawing up the final interview schedule. In the third stage, thirty-two interviews were held, lasting on average an hour and a half.

\section{The genolyptus network}

Brazil is highly competitive in the paper and pulp sector, thanks to its natural resources but also due to the development of modern silviculture technologies and growing $R \& D$ investments in the sector. Over the last few years Brazil has significantly increased research related to many native species. These efforts have increased the country's productivity. However, in the early 2000s, there was a widespread perception that the growth of competitiveness required a more aggressive posture in terms of R\&D investments. However, the individual companies lacked the technological and financial resources to maintain a sustained effort in terms of engaging in continuous innovation, building specific knowledge, investing in specialized equipment, and reducing uncertainty in terms of return on investment. 
The network was set up to serve these aims in February 2002. It was perceived as a major project in terms of its capacity to articulate recognized competencies in the industrial sector (i.e., 14 companies) and in research institutions (i.e., 7 universities and Embrapa - Brazilian Agricultural Research Corporation, a governmental research institute). The network's goals were to discover, validate and characterize the functions of the eucalyptus genes which are economically important production and forest development programs. To do so, the network aimed at ensuring that partners had access to methods and scientific information that could be implemented in their development programs.

The network partners relied on the design of contracts and work plans undertaken during the network's formation process. However, it also relied on a set of standards which emerged in a trial-anderror process. The need to set up governance structures characterized the initial discussions held in the network. As a result, drawing-up the contract, in which the formal rules were established, took more than a year. The establishment of these rules provided a reference, guiding the work. However, as the network developed, formal rules gave way to a set of much more informal rules that went on to govern the network's day-to-day operations. According to the interviewees, such informality could be ascribed to experience derived from previous partnerships and from personal and institutional relationships in the sector.

The above characteristics justify the choice of the Genolyptus case as the basis for this research. In the beginning of its history the network was characterized as a pioneer project in Brazil, not only in terms of the breadth of its goals, but also in terms of its ability to combine and articulate skills in the relevant industries and research institutions around a national network. It is also worth mentioning that the network had records of all documents produced throughout its history and made them available for analysis in this study.

Besides, the choice of Genolyptus as an illustrative case was due to the fact that when the network was investigated, we faced the same elements that compose the analysis on pro-social motivation in the organizational environment. So it represented an opportunity to investigate if the framework of how prosocial motivation can be applied in a network environment. Therefore, we consider that its analysis will represent a breakthrough in literature, since no previous studies that discuss this concept in the context of networks exist. However, since this is a single case study it is suggested that further research need to be conducted to confirm this evidence or not.

\section{Coordinating sub-projects and tasks}

Although the network was launched in 2002, the idea had been launched in 2000, in a forum that brought together the sector's leaders. A discussion on a preliminary design began and researchers from a few universities were invited to develop it. Once developed, it was sent to the companies, with a questionnaire to assess preliminary expectations. The product of this joint effort became the project's initial rough-draft, which from then on, counted on the contributions of all involved. A number of factors during the network's set-up and implementation phase contributed to creating a common understanding of the project and to stressing the interdependence of its sub-projects and the participating parties. The technical design promoted the convergence of interests, since it dealt with basic scientific research (the interest of the universities) and experimental improvements (the interest of the companies) that were highly complementary. As a manager in one of the partner companies stated; "People who are in the company have superior tacit knowledge. The staff of universities has another kind of knowledge, they study, possess theory, have time to think. This is a highly complementary relation”. Similarly, a professor from one of the participating universities stated that the knowledge that is being generated is very advanced and is extremely multidisciplinary ... it is something that only come into existence and is well used because it is done as a group ... it is the multidisciplinary nature and diversity of the people that makes the projects have more or less success.

The data strongly suggests that the capacity to motivate participants over the course of the network's creation was a decisive factor for its success. This motivation enabled communication processes and training programs that ensured recurrent exchange of information among participants, in 
turn facilitating ongoing coordination. In fact, the training programs were perceived as an important instrument for generating the understanding of goals, tasks and interdependencies that precede the formation of joint production motivation. Throughout the network's existence, participants used various communication mechanisms and were able to keep up to date with the evolution of work-packages. Many meetings were held to demonstrate project progress, share experience and so on.

Conflict resolution. Decisions were based on a broad discussion process, where open debate of various perspectives was emphasized. The following, taken from a project participants' email, is typical for how unanticipated contingencies were handled: "However, since there is no provision for it explicitly in the work plan ... I believe it is important to submit the appraisal of all and undertake a global action". This consensual decision-making standard was crucially important for work development, keeping up with schedule, minimizing conflicts, increasing information symmetry and maintaining the alignment between the sub-projects and the network. In particular, the many e-mails that were exchanged between members of the network manifest a flexible, open and adaptive behavioral stance, even when non-trivial modifications were required, implying the commitment of more work-effort, resources and time. Strikingly, arguments were always based on the best interest of the network and the achievement of its objectives, that is, on group rather than individual goals. As a manager of one of the participating companies summarized: "What was sought was always an attempt at consensus ... the coordinator was very clever in this regard... But people were not complacent with each other in order to accept opinions that they did not agree with, I think a team spirit was developed, where everyone had the opportunity to express their way of saying no."

Shared purpose. The Genolyptus network was formed by highly experienced researchers. Its objective and composition exposed the group to opportunities for growth and professional updating. Moreover, the knowledge base used was characterized by high levels of cumulativeness, which influenced the decision to join in and increased the level of dedication of all participants. The hopes of acquiring unique know-how, which would define the future advancement of a research field, prompted situations where everyone involved was willing to contribute to the execution of tasks. These behaviors were driven by a shared sense of purpose; in particular, network members entertained high expectations that the knowledge to be created in the network would become a source of new competitive advantages that would drive the sector.

While the network members were clearly oriented towards the goals of the network as a whole, there was a significant element of reciprocity: Everyone contributed at a high level and expected everyone else to do the same. This was partly prompted by a recognition that efforts were highly complementary; thus, successful knowledge development was only possible through the combination of individual skills and the competencies of the participating institutions. All of these factors contributed to the emergence of a feeling among the members that they were part of a sustainable elite group, which in turn encouraged participation and contributed to the project's success. As one of the participating university professors stated: "When the project is done in two years I'm sure we'll all be connected ... technically we get along very well. We complement each other, this is a business that will last ... until I retire".

Monitoring. In order to support and sustain such involvement, the network relied on a monitoring system. Evaluations were made using established targets and schedules, and via publication of the work progress in written minutes. Furthermore, during general meetings with network members, the coordinator would present the specific conditions of each sub-project. A 0 -to-10 rating system reflected the level of goal-achievement vis-à-vis what was expected in the work plan. In cases of disparities between what was expected and what was de facto achieved, the sub-project's coordinator had to justify why the work had not been concluded and what was pending for its conclusion. In this way, they considered both quantitative and qualitative measures, since the justification made room for process evaluation. Given the history of organizational relationships and of individuals that characterized this industry, there were also informal evaluations through telephone calls and e-mails.

Hierarchical Structure. The interview data establish that there was a consensus among the participants that the overall network coordinator's abilities to deal with the network's diversity and keep 
the group spirit thriving were key elements that enabled the project to succeed. The coordinator had an excellent reputation as a highly competent technician and researcher, and a skilled project manager. He was responsible for the project's initial concept and design. During the elaboration phase, he was in charge of the integration between future members and inviting companies to participate in the project. He headed the definition of the project's chief guidelines (objectives, work plan etc.). Overall, however, his authority was fundamentally knowledge-based, that is, based on his reputation for excellence in several dimensions, rather than formal authority-of-the-office.

Decision-making processes. The formal tasks and activity patterns were spelled out in the contract and contributed to a high degree of transparency. Yet, network management had to address the fact that participating companies and universities were in potential competition, definitely not a trivial management task. In addition, there were also renowned and recognised sector leaders and strong personal and professional relationships among the network actors. These individuals held strong bargaining powers qua their positions. To address these challenges the coordinator adopted a standard of network coordination and decision-making based on consensus and equality among participants. There were no established hierarchies or priorities among them, and all votes had the same weight. Decisions were arrived at by means of extensive debates, followed by a voting session with simple majority voting determining the outcome: "An important point in this network is the coordination and its ability to manage attrition, but the decision making is collective, is the majority. So it may be that we will take all afternoon to make a decision because there are many people involved ... control is solely in the hand of the coordinator, his competence to do and everything, but decisions are made jointly" (interview with manager of a partner company). When issues were related to a specific competence, the adopted standard was to debate and to explicitly rely on the network specialists' knowledge. In other words, decision-making authority tended to be exercised by means of majority decisions in the case of general issues, while knowledge-based authority was invoked in the case of specific issues.

\section{Discussion: pro-social motivation in the genolyptus network}

Research suggests that pro-social motivations may thrive under a framework defined by a sense of shared purpose (Kogut \& Zander, 1996), trust (Nahapiet \& Ghoshal, 1998), and a shared understanding of interdependencies (Lindenberg \& Foss, 2011), that is, individuals share a perception of a joint production effort and are motivated to take part in it. As we have pointed out, a number of contributions to the knowledge-based view in organizational theory and strategic management suggest that only firms can successfully contribute these conditions. In contrast, we argue that the Genolyptus network was characterized by these exact conditions and as such was capable of creating pro-social motivations.

\section{Perceived joint production}

An individual's motivation for joint production requires a clear understanding of the tasks performed individually and by the team, including a clear understanding of how the focal individual's effort is connected to those of other individuals in the joint production. The maintenance of this motivation requires a communication process that ensures both recurrent exchanges of information as well as conflict-resolution mechanisms. Establishing the Genolyptus network was a process which contributed to the creation of these conditions, as we have detailed. In addition, the interview data suggest that the communication process in the network was crucially important for maintaining the sense of shared purpose and clarifying to all participants the exact nature of the division of labor in the network. The many workshops, training courses, and technical visits of network members to each other played similar roles and also helped to build strong trust-based relations.

\section{Cognition and symbolic management}

Joint production motivation requires a shared sense of shared purpose. This can often be established through rites, rituals, norms, and conventions. Literature highlights the importance of 
governance mechanisms in stabilizing this common direction and, hence, making room for cooperative work (Kogut \& Zander, 1996). The case evidence shows that participants invested significant time discussing the contract and they made great effort to construct a set of tools and routines to guide the day-to-day activities. But is this sufficient to promote joint production motivation?

In an analysis of cooperative arrangements, Lindenberg (2000, p. 20) warned against seeing “... governance instrument as 'ideal' without having analyzed the question of what interests need to be aligned and what signals are consensually taken as positive relational signals in a particular industry". Lindenberg analyzed such relational signals in five distinct situations and concluded that deviations in any one of them indicated problems with the cooperative frame stability. He specifically argues that a well-constructed governance structure must consider the social context of the organization, how it contributes to the normative goal-frame and, consequently, to joint production motivation. Indeed, to a large extent the Genolyptus network could build from existing trust relations within the relevant industries. As a company representative expressed, the basic network contract "was implemented within a foundation of trust that already existed in companies ... the spirit of cooperation is already very high."

Such pre-existing trust relations were highly conducive to the creation of network-specific values and codes which in turn helped to create and sustain joint production motivation: "There is an overall agreement, to be sure. This may not be directly reflected in the contract in terms of commitment, but there is set of values that animate this network, and this set is an instrument of pressure" (interview with manager of a partner company).

\section{Recognition-based rewards structure}

Lindenberg and Foss (2011) argued that rewards can support the normative goal frame when they are connected to joint outcomes. The Genolyptus case provides evidence of such contribution, since individual rewards not only reinforced the normative goal frame, but were made to depend on the overall outcome of the activities of the network. Thus, the data show that participants understood that their own personal income, status, etc. was connected to the interdependence of the tasks in the network. Consequently, individuals with greater skills to act collaborativelly as a group, with stronger technical and relational reputations, would probably distinguish themselves in the industry. Still, these incentives played out in a particular social context: "The forestry sector is slightly different ... competing firms form alliances around common goals and even allow their genetic material to be made available for the network ... In general there is a very great friendship between colleagues in the field. And you know that any interaction must have a certain affinity. And this already exists in some form. Genolyptus was a part of all this" (interview with a professor from a partner university).

Thus, the industry, and in turn the network, created opportunities for aligning goals and, from a long-term perspective, brought the individual goal and, thus, the reward structure, close to the normative goal.

\section{Knowledge-based authority design}

When trying to achieve goals through joint production, authority systems should not be legitimized through hierarchy; rather, the group should be directed towards joint production by means of the exercise of authority that is perceived by participating individuals as capable of contributing with essential know-how and information that are needed to achieve the joint goal. The interview data supports the interpretation that the Genolyptus network's coordinator possessed exactly this capacity to guide his team to joint production. Indeed, the data reflects a general perception among the network participants that he possessed superior judgement, since he was perceived as a competent technician and researcher, in addition to being a skilled project manager. "He is one of the leading exponents of genomics in Brazil, if not the main one. And the network has the advantage that he is a natural leader, and people respect him" (interview with coordinator company). 
Furthermore, the coordinator's characteristics were reinforced by the decision-making processes adopted. Consensus and respect for each member's specific know-how were the Genolyptus coordinator's twin pillars. This way, even though the network management revolved around its coordinator, network leadership was like a moving target and was exercised according to the specificities of the activities to be carried out. In such a case, the coordinator focused on providing the necessary conditions for information symmetry, establishing an open debate and trying to reach a consensus. Thus, the possibility of conflicts was minimized.

\section{Conclusion}

\section{Research question and key finding}

An influential stream of thinking on the role and function of firms in a market economy asserts that firms exist because they provide rewards and motivation geared to the sourcing, combination, creation and sharing of knowledge (Ghoshal \& Moran, 1996; Hodgson, 1998; Kogut \& Zander, 1992, 1996; Madhok, 1996), and that providing such rewards and motivation is beyond the capabilities of markets and other forms of non-firm economic organization. These contributions are seldom explicit or detailed about the motivational mechanisms operating in firms, providing them with their supposedly unique capability of organizing delicate knowledge processes. Lindenberg and Foss (2011) which explicitly speaks to the issue of how pro-social motivation in firms can be initiated and maintained. However, on the face of it, the argument that only firms can truly supply the pro-social motivation that supports various knowledge-processes flies in the face of phenomena such as open-source software development, Wikipedia, etc. that are arguably at least partly based on voluntary pro-socially motivated efforts by legally independent individuals. This raises the question whether pro-social motivation can exist beyond the boundaries of firms, for example, in networks, and, if so, what supports such pro-social motivation?

We have documented a case that, relative to these theoretical expectations, is clearly a deviant case: All of the management and organization practices which according to Lindenberg and Foss (2011), are necessary to initiate and maintain joint production motivation were in fact present in the Genolyptus network. And yet, the participants in that network remained legally independent entities; in fact, many of the participants were independent business firms and potential competitor. Specifically, the mechanisms that support pro-social motivations in firms - namely, intensive communication, rewards that are tied to joint outcomes, knowledge-based authority, and consensual decision-making — are also the mechanisms that support pro-social motivations in the non-firm governance structure we examined.

\section{Future research}

Our finding may be seen as a partial confirmation of Grandori's $(1997,2001)$ argument that governance structures are not fundamentally distinguished in terms of the governance instruments they deploy to influence behaviors: The same governance mechanisms that support pro-social motivation in firms can also be found in networks. Future research should deal with whether markets are also capable of mimicking such mechanisms. Experimental research in social psychology and behavioral economics (e.g., Fehr \& Fischbacher, 2002; Liberman, Samuels, \& Ross, 2004) suggests that pro-social motivation in fact do exist in markets. The question is what sustains such motivation in markets? However, this research also suggests that pro-social motivation is in lower supply in market than in non-market contexts.

Given this, we propose a research program dedicated to examining the relative advantages of firms and non-firm economic organizations with respect to fostering pro-social motivation and the mechanisms these different governance structures deploy to foster such motivation. Our case evidence suggests that pro-social motivations can exist in a network, and, in fact, thrive. However, we cannot 
establish in any conclusive way whether these motivations would have thrived better or worse in, say, an integrated operation that included all of the participants in the network (i.e., a Genolyptus firm). Similarly, we cannot establish any differences in the intensity with which networks and firms deploy the instruments that may support pro-social motivations. It is conceivable that firms may have an advantage here, because of their easier access to mechanisms of dispute resolution and information sharing (Williamson, 1996). If that is the case, the knowledge-based argument that we started out from in this research is vindicated, albeit in a more precise form: Although pro-social motivations can exist beyond the boundaries of the firm, firms have an organizational advantage when it comes to building and sustaining such motivations.

\section{References}

Adler, P. S. (2001). Market, hierarchy and trust: the knowledge economy and the future of capitalism. Organization Science, 12(2), 215-234. doi: 10.1287/orsc.12.2.215.10117

Alchian, A. A., \& Demsetz, H. (1972). Production, information costs, and economic organization. American Economic Review, 62(5), 772-795. doi: 10.2307/1815199

Brewer, M. B., \& Gardner, W. (1996). Who is this "we"? Levels of collective identity and self representations. Journal of Personality and Social Psychology, 71(1), 83-93. doi: 10.1037/00223514.71.1.83

Brickson, S. L. (2005). Organizational identity orientation: forging a link between organizational identity and organizations' relations with stakeholders. Administrative Science Quarterly, 50(4), 576-609. doi: 10.2189/asqu.50.4.576

Brickson, S. L. (2007). Organizational identity orientation: the genesis of the role of the firm and distinct forms of social value. Academy of Management Review, 32(3), 864-888. doi: 10.5465/AMR.2007.25275679

Brief, A. P., \& Motowidlo, S. J. (1986). Prosocial organizational behaviors. Academy of Management Review, 11(4), 710-725. doi: 10.5465/AMR.1986.4283909

Deckop, J. R., Mangel, R., \& Cirka, C. C. (1999). Getting more than you pay for: organizational citizenship behavior and pay-for-performance plans. Academy of Management Journal, 42(4), 420-428. doi: $10.2307 / 257012$

De Dreu, C. K. W., Nijstad, B. A., \& Knippenberg, D. van (2008). Motivated information processing in group judgment and decision making. Personality and Social Psychology Review, 12(1), 22-49. doi: $10.1177 / 1088868307304092$

Dyer, W. G., Jr., \& Wilkins, A. L. (1991). Better stories, not better constructs, to generate better theory: a rejoinder to Eisenhardt. Academy of Management Review, 16(3), 613-619. doi: 10.5465/AMR.1991.4279492

Fehr, E., \& Fischbacher, U. (2002). Why social preferences matter - the impact of non-selfish motives on competition, cooperation and incentives. The Economic Journal, 112(478), C1-C33. doi: $10.1111 / 1468-0297.00027$

Ferraro, F., Pfeffer, J., \& Sutton, R. I. (2005). Economics language and assumptions: how theories can become self-fulfilling. Academy of Management Review, 30(1), 8-24. doi: 10.5465/AMR.2005.15281412

Förster, J., Liberman, N., \& Higgins, E. T. (2005). Accessibility from active and fulfilled goals. Journal of Experimental Social Psychology, 41(3), 220-239. doi: 10.1016/j.jesp.2004.06.009 
Foss, N. J., \& Lindenberg, S. M. (2011). Managing joint production motivation: the role of goal framing and governance mechanisms. Academy of Management Review, 36(3), 500-525. doi: 10.5465/AMR.2011.61031808.

Foss, N. J., \& Lindenberg, S. (2012). Teams, team motivation, and the theory of the firm. Managerial and Decision Economics, 33(5/6), 369-383. doi: 10.1002/mde.2559

Frey, B. S., Luethi, R., \& Osterloh, M. (2011). Community enterprises: an institutional innovation [CESifo Working Paper Series $\mathrm{N}^{\mathrm{o}}$ 3428]. Retrieved from http://papers.ssrn.com/sol3/papers.cfm?abstract_id=1831123

Ghoshal, S. (2005). Bad management theories are destroying good management practices. Academy of Management Learning \& Education, 4(1), 75-91. doi: 10.5465/AMLE.2005.16132558

Ghoshal, S., \& Moran, P. (1996). Bad for practice: a critique of the transaction cost theory. Academy of Management Review, 21(1), 13-47. doi: 10.5465/AMR.1996.9602161563

Gollwitzer, P. M., \& Bargh, J. A. (Eds.). (1996). The psychology of action: linking cognition and motivation to behavior. New York: Guilford Press.

Grandori, A. (1997). An organizational assessment of interfirm coordination modes. Organization Studies, 18(6), 897-925. doi: 10.1177/017084069701800601

Grandori, A. (2001). Neither hierarchy nor identity: knowledge-governance mechanisms and the theory of the firm. Journal of Management and Governance, 5(3/4), 381-399. doi: 10.1023/A:1014055213456

Grant, A., \& Dutton, J. (2012). Beneficiary or benefactor: are people more prosocial when they reflect on receiving or giving? Psychological Science, 23(9), 1033-1039. doi: $10.1177 / 0956797612439424$

Haslam, S. A., Powell, C., \& Turner, J. C. (2000). Social identity, self-categorization, and work motivation: rethinking the contribution of the group to positive and sustainable organisational outcomes. Applied Psychology, 49(3), 319-339. doi: 10.1111/1464-0597.00018

Hedström, P. (2005). Dissecting the social: on the principles of analytical sociology. Cambridge, UK: Cambridge University Press.

Higgins, E. T., \& Pittman, T. S. (2008). Motives of the human animal: comprehending, managing, and sharing inner states. Annual Review of Psychology, 59, 361-385. doi: 10.1146/annurev.psych.59.103006.093726

Hodgson, G. M. (1998). Competence and contract in the theory of the firm. Journal of Economic Behavior and Organization, 35(2), 179-201.

Isaac, R. M., Mathieu, D., \& Zajac, E. E. (1991). Institutional framing and perceptions of fairness. Constitutional Political Economy, 2(3), 329-370. doi: 10.1007/BF02393135

King, G., Keohane, R. O., \& Verba, S. (1994). Designing social inquiry: scientific inference in qualitative research. Princeton: Princeton University Press.

Klein, B., \& Leffler, K. B. (1981). The role of market forces in assuring contractual performance. Journal of Political Economy, 89(4), 615-641. doi: 10.2307/1833028

Kogut, B., \& Zander, U. (1992). Knowledge of the firm, combinative capabilities, and the replication of technology. Organization Science, 3(3), 383-397. doi: 10.1287/orsc.3.3.383 
Kogut, B., \& Zander, U. (1996). What firms do? Coordination, identity, and learning. Organization Science, 7(5), 502-518. doi: 10.1287/orsc.7.5.502

Kozlowski, S. W. J., \& Ilgen, D. R. (2006). Enhancing the effectiveness of work groups and teams. Psychological Science in the Public Interest, 7(3), 77-124. doi: 10.1111/j.15291006.2006.00030.x

Krippendorff, K. (2004). Content analysis: an introduction to its methodology (2nd ed.). Thousand Oaks, CA: Sage Publications.

Kruglanski, A. W., \& Köpetz, C. (2009). What is so special (and non-special) about goals? A view from the cognitive perspective. In G. B. Moskowitz \& H. Grant (Eds.), The psychology of goals (pp. 27-55). New York: Guilford Press.

Langley, A. (1999). Strategies for theorizing from process data. Academy of Management Review, 24(4), 691-710. doi: 10.5465/AMR.1999.2553248

Ledyard, J. O. (1995). Public goods: a survey of experimental research. In J. H. Kagel \& A. E. Roth (Eds.), The handbook of experimental economics (pp. 111-194). Princeton, NJ: Princeton University Press.

LePine, J. A., Erez, A., \& Johnson, D. E. (2002). The nature and dimensionality of organizational citizenship behavior: a critical review \& meta-analysis. Journal of Applied Psychology, 87(1), 5265. doi: 10.1037/0021-9010.87.1.52

Liberman, V., Samuels, S. M., \& Ross, L. (2004). The name of the game: predictive power of reputations versus situational labels in determining prisoner's dilemma game moves. Personality and Social Psychology Bulletin, 30(9), 1175-1185. doi: 10.1177/0146167204264004

Lindenberg, S. (2000). It takes both trust and lack of mistrust: the workings of cooperation and relational signaling in contractual relationships. Journal of Management and Governance, 4(1-2), 11-33. doi: 10.1023/A:1009985720365

Lindenberg, S. (2008). Social rationality, semi-modularity and goal-framing: what is it all about? Analyse \& Kritik, 30(2), 669-687.

Lindenberg, S., \& Foss, N. J. (2011). Managing joint production motivation: the role of goal framing and governance mechanisms. Academy of Management Review, 36(3), 500-525. doi: 10.5465/AMR.2011.61031808.

Madhok, A. (1996). The organization of economic activity: transaction costs, firm capabilities and the nature of governance. Organization Science, 7(5), 577-590. doi: 10.1287/orsc.7.5.577

Mathieu, J. E., Maynard, T. M., Rapp, T., \& Gilson, L. (2008). Team effectiveness 1997-2007: a review of recent advancements and a glimpse into the future. Journal of Management, 34(3), 410-476. doi: $10.1177 / 0149206308316061$

Moorman, R. H., \& Blakely, G. L. (1995). Individualism-collectivism as an individual difference predictor of organizational citizenship behavior. Journal of Organizational Behavior, 16(2), 127 142. doi: $10.1002 /$ job.4030160204

Nahapiet, J., \& Ghoshal, S. (1998.) Social capital, intellectual capital, and the organizational advantage. Academy of Management Review, 23(2), 242-266. doi: 10.5465/AMR.1998.533225

Organ, D. W., Podsakoff, P. M., \& MacKenzie, S. B. (2006). Organizational citizenship behavior: its nature, antecedents, and consequences. Thousand Oaks, CA: Sage Publications. 
Osterloh, M., \& Frey, B. S. (2000). Motivation, knowledge transfer, and organizational forms. Organization Science, 11(5), 538-550. doi: 10.1287/orsc.11.5.538.15204

Ostrom, E., Walker, J., \& Gardner, R. (1992). Covenants with and without a sword: self-governance is possible. American Political Science Review, 86(2), 404-417. doi: 10.2307/1964229

Penner, L. A., Dovidio, J. F., Piliavin, J. A., \& Schroeder, D. A. (2005). Prosocial behavior: multilevel perspectives. Annual Review of Psychology, 56, 365-392. doi: 10.1146/annurev.psych.56.091103.070141

Podsakoff, P. M., Ahearne, M., \& MacKenzie, S. B. (1997). Organizational citizenship behavior and the quantity and quality of work group performance. Journal of Applied Psychology, 82(2), 262-270. doi: 10.1037/0021-9010.82.2.262

Podsakoff, P. M., \& MacKenzie, S. B. (1994). Organizational citizenship behaviors and sales unit effectiveness. Journal of Marketing Research, 31(3), 351-363. doi: 10.2307/3152222

Podsakoff, P. M., \& MacKenzie, S. B. (1997). Impact of organizational citizenship behavior on organizational performance: a review and suggestions for future research. Human Performance, 10(2), 133-151. doi: 10.1207/s15327043hup1002_5

Posner, M. I., \& Petersen, S. E. (1990). The attention system of the human brain. Annual Review of Neuroscience, 13, 25-42. doi: 10.1146/annurev.ne.13.030190.000325

Sandel, M. J. (2013). Market reasoning as moral reasoning: why economists should re-engage with political philosophy. Journal of Economic Perspectives, 27(4), 121-140. doi: 10.1257/jep.27.4.121

Sebanz, N., Bekkering, H., \& Knoblich, G. (2006). Joint action: bodies and minds moving together. Trends in Cognitive Science, 10(2), 70-76. doi: 10.1016/j.tics.2005.12.009

Servaes, H., \& Tamayo, A. (2013). The impact of corporate social responsibility on firm value: the role of customer awareness. Management Science, 59(5), 1045-1061. doi: 10.1287/mnsc.1120.1630

Shah, J. Y., Friedman, R., \& Kruglanski, A. W. (2002). Forgetting all else: on the antecedents and consequences of goal shielding. Journal of Personality and Social Psychology, 83(6), 1261-1280. doi: 10.1037/0022-3514.83.6.1261

Shamir, B. (1990). Calculations, values, and identities: the sources of collectivistic work motivation. Human Relations, 43(4), 313-332. doi: 10.1177/001872679004300402

Shamir, B. (1991). Meaning, self and motivation in organizations. Organization Studies, 12(3), 405424. doi: $10.1177 / 017084069101200304$

Spender, J. C. (1996). Making knowledge the basis of a dynamic theory of the firm. Strategic Management Journal, 7(S2), 45-62. doi: 10.1002/smj.4250171106

Strauss, A. L., \& Corbin, J. M. (1990). Basic of qualitative research. Grounded theory procedures and techniques. Newbury Park, CA: Sage Publications.

Tomasello, M., Carpenter, M., Call, J., Behne, T., \& Moll, H. (2005). Understanding and sharing intentions: the origin of cultural cognition. Behavioral and Brain Sciences, 28(5), 675-735.

Van Knippenberg, D. (2000). Work motivation and performance: a social identity perspective. Applied Psychology, 49(3), 357-371. doi: 10.1111/1464-0597.00020 
Walz, S. M., \& Niehoff, B. P. (2000). Organizational citizenship behaviors: their relationship to organizational effectiveness. Journal of Hospitality \& Tourism Research, 24(3), 301-319. doi: $10.1177 / 109634800002400301$

Weick, K. E., \& Roberts, K. H. (1993). Collective mind in organizations: heedful interrelating on flight decks. Administrative Science Quarterly, 38(3), 357-381. doi: 10.2307/2393372

Weinstein, N., \& Ryan, R. M. (2010). When helping helps: autonomous motivation for prosocial behavior and its influence on well-being for the helper and recipient. Journal of Personality and Social Psychology, 98(2), 222-244. doi: 10.1037/a0016984

Williamson, O. E. (1996). The mechanisms of governance. Oxford, UK: Oxford University Press.

Wrzesniewski, A., \& Dutton, J. E. (2001). Crafting a job: revisioning employees as active crafters of their work. Academy of Management Review, 26(2), 179-201. doi: 10.5465/AMR.2001.4378011 


\section{APPENDIX}

\begin{tabular}{|c|c|c|}
\hline $\begin{array}{c}\text { List of Interviewees } \\
\text { First Phase - Interviewee }\end{array}$ & Institution & Position \\
\hline $\mathrm{A}$ & 1 & Director of Institutional Relationships \\
\hline $\mathrm{B}$ & 2 & \multirow{4}{*}{ Professor } \\
\hline $\mathrm{C}$ & \multirow{2}{*}{3} & \\
\hline $\mathrm{D}$ & & \\
\hline $\mathrm{E}$ & 4 & \\
\hline $\mathrm{F}$ & 5 & Forestry R\&D Coordinator \\
\hline $\mathrm{G}$ & 6 & R\&D Manager \\
\hline $\mathrm{H}$ & 7 & Professor \\
\hline I & 8 & Researcher \\
\hline \multicolumn{3}{|c|}{ Second Phase } \\
\hline I & 8 & Researcher \\
\hline \multicolumn{3}{|c|}{ Third Phase } \\
\hline $\mathrm{J}$ & \multirow{2}{*}{9} & \multirow{3}{*}{ Researcher } \\
\hline $\mathrm{L}$ & & \\
\hline I & 8 & \\
\hline M & 5 & R\&D Coordinator \\
\hline $\mathrm{N}$ & \multirow{5}{*}{6} & R\&D Manager \\
\hline $\mathrm{O}$ & & Researcher \\
\hline $\mathrm{P}$ & & Project Coordinator \\
\hline Q & & Researcher \\
\hline $\mathrm{R}$ & & \\
\hline $\mathrm{S}$ & \multirow{2}{*}{10} & Project Coordinator \\
\hline $\mathrm{T}$ & & Researcher \\
\hline $\mathrm{U}$ & \multirow{3}{*}{11} & Forestry R\&D Coordinator \\
\hline $\mathrm{V}$ & & R\&D Director \\
\hline $\mathrm{X}$ & & \multirow{2}{*}{ Researcher } \\
\hline $\mathrm{Z}$ & 12 & \\
\hline AA & \multirow{3}{*}{13} & $\mathrm{R} \& \mathrm{D}$ Coordinator \\
\hline $\mathrm{BB}$ & & Researcher \\
\hline $\mathrm{CC}$ & & Manager of Planning and forestry research \\
\hline $\mathrm{DD}$ & \multirow{3}{*}{14} & Coordinator of genetic improvement \\
\hline $\mathrm{EE}$ & & R\&D Manager \\
\hline $\mathrm{FF}$ & & \multirow{2}{*}{ Researcher } \\
\hline GG & 15 & \\
\hline
\end{tabular}




\begin{tabular}{|c|c|c|}
\hline $\mathrm{HH}$ & \multirow{3}{*}{1} & R\&D Coordinator \\
\hline II & & Director of Institutional Relationships \\
\hline JJ & & R\&D Manager \\
\hline $\mathrm{LL}$ & 4 & Professor \\
\hline MM & 16 & Researcher \\
\hline NN & 2 & \multirow{4}{*}{ Professor } \\
\hline $\mathrm{OO}$ & \multirow{3}{*}{7} & \\
\hline PP & & \\
\hline QQ & & \\
\hline RR & 17 & R\&D Manager \\
\hline
\end{tabular}

